\title{
CLAVES PARA UN RÉGIMEN INTERNACIONAL DE LA CLONACIÓN HUMANA
}

\section{Daniel Ignacio GARCÍA SAN JOSÉ*}

RESUMEN: En el presente trabajo el autor presenta la tesis de la necesidad de superar una aproximación dialéctica a la investigación y experimentación en materia de clonación humana, según la cual se está a favor o en contra de la misma en razón de la libertad de la ciencia y del mercado o considerando la dignidad humana. Para el autor, la cuestión de la investigación y experimentación en materia de clonación humana precisa de una lectura integradora como paso previo a una regulación que, por la misma naturaleza de su ámbito jurídico material, ha de venir dada, necesariamente, por el derecho internacional.

ABSTRACT: In this paper the author would support the necessity of avoiding dialectical approaches to the research and experimentation with cloning pre-embryo human cells. According to such dialectic view, any discussion on this topic would only be focused on the 'pros' and 'cons' considering freedom of science and market, on the one hand, and the human dignity, on the other. The author would believe that this matter regarding the research with cloning human cells requires an integrative reading as a previous stage for a worldwide binding regulation which, necessarily, must be provided by International Law.

RÉSUMÉ: Dans le présent travail l'auteur soutien la thèse selon laquelle il serait nécessaire surmonter la dialectique autour de la recherche et de l'expérimentation pour le clonage des cellules humaines pré-embryonnaires.L'auteur considère préférable l'adoption d'une lecture intégrative des questions en jeux, telles comme la liberté de la science et des marchés, d'un côté, et la défense de la dignité humaine, de l'autre. Il serait ainsi condition pour une régulation internationale de la main du Droit international.

* Doctor en derecho por la Universidad de Sevilla. Diploma del Centro de Estudios y de Investigaciones de la Academia de Derecho Internacional de La Haya (Holanda). Diploma with distinction del Eric Castrén Institut de Derecho Internacional. Profesor visitante en las universidades de Viadrina (Alemania) y Coimbra (Portugal). 
SUMARIO: I. Introducción.Un debate abierto. II. Los condicionantes económicos y éticos como motor y freno de una regulación uniforme. III. La dignidad humana como punto de partida para una necesaria legislación internacional en esta materia. IV. Los derechos humanos inalienables como concreción de la dignidad de todo ser humano. V. Una aproximación global e integradora para una regulación internacional de la clonación humana. VI. Conclusiones.

\section{INTRODUCCIÓN. UN DEBATE ABIERTO}

Aunque existen varios discursos en torno a la investigación y experimentación en materia de clonación humana, básicamente destacan aquéllos que plantean ésta en el marco de un debate entre dos postulados enfrentados: de un lado estaría la libertad de la ciencia auspiciada en gran medida ante las expectativas de la rentabilidad económica derivada de la libre comercialización de los descubrimientos que puedan realizarse. De otro lado, los derechos humanos inalienables que se piensan están expuestos a un grave riesgo de vulneración si se permite dicha experimentación e investigación genética. La regulación que se ha dado a la clonación humana tanto a nivel interno como internacional, se encontraría en gran medida influenciada por este debate dialéctico entre los defensores y detractores de la investigación y experimentación sobre clonación humana desde los planteamientos descritos.

Esta situación provoca una cierta dosis de insatisfacción en el jurista por dos razones: la primera se debe al hecho de ubicar en tan reducidos parámetros la regulación internacional de la clonación humana, obviando la existencia de otras consideraciones que despectivamente pueden ser calificadas de "menores". En segundo lugar, es igualmente fuente de insatisfacción el situar el debate en torno a la clonación humana en esta dialéctica pues supone renunciar a una opción ecléctica e integradora de todas las sensibilidades y cuestiones implicadas. Esta sería, en mi opinión, la razón primera de que aún no exista un amplio y generalizado consenso a nivel internacional sobre la normativa básica que debe regir la investigación y experimentación en materia de clonación humana. El aceptar un reductivismo de la cuestión a un debate entre los defensores 
de la dignidad humana y los derechos inalienables del ser humano frente a los que promueven los avances de la ciencia y la comercialización en virtud del régimen internacional de patentes de los posibles descubrimientos que puedan obtenerse, supone empobrecer el debate sobre la clonación humana y los eventuales intentos de materializarlo en resultados concretos que no sean mera retórica vacía de contenido y carente de toda eficacia en la práctica. Por esta razón, desde estas páginas se plantea el carácter erróneo de un discurso sobre la clonación humana sustentado en el binomio que contrapone ciencia-mercado a ética-moral y se apunta la necesidad de optar por una aproximación global, integradora y más coherente con la multiplicidad de la pluralidad de cuestiones - incluso de aquellas que molesten, choquen o resulten indiferentes - en la investigación y experimentación en materia de clonación humana.

\section{LOS CONDICIONANTES ECONÓMICOS Y ÉTICOS COMO MOTOR Y FRENO DE UNA REGULACIÓN UNIFORME}

La única declaración interpretativa que acompaña la firma del Protocolo Adicional al Convenio relativo a los Derechos Humanos y la Biomedicina por el que se prohíbe la clonación de seres humanos, introducida por los Países Bajos, suscitó una cierta polémica que se enmarca en el contexto del debate ético sobre la clonación humana. Pretendía el gobierno holandés dejar constancia de modo expreso de su interpretación del término "dignidad del ser humano", presente en el párrafo primero del artículo 1 de dicho protocolo y piedra angular del mismo, ${ }^{1}$ en el sentido de que "estaba referido exclusivamente a un ser humano individual, por ejemplo, la dignidad de quien ha nacido". ${ }^{2}$ Con esta declaración interpretativa, los Países Bajos se distanciaban de aquellos Estados participantes en la redacción del protocolo por el que se prohíbe la clonación humana - como La Santa Sede - que apelaban a una dimensión ética de la clo-

1 Artículo 1. 1: "Se prohíbe toda intervención que tenga por finalidad crear un ser humano genéticamente idéntico a otro ser humano vivo o muerto".

2 El texto de esta declaración interpretativa puede consultarse en la página Web del Consejo de Europa www.coe.int en el apartado Treaty Series. 
nación humana desde una consideración de la existencia del ser humano desde el mismo instante de la concepción. ${ }^{3}$

Aunque en los más recientes textos internacionales de protección de derechos humanos parece prevalecer la opción del término "persona" en relación con la clonación humana, en un sentido próximo al pretendido por los Países Bajos en su declaración interpretativa, ${ }^{4}$ en mi opinión esta declaración sería difícilmente compatible con el sentido que al término "ser humano" se da en el texto principal - el Convenio relativo a los Derechos Humanos y la Biomedicina- del que es secundario el Protocolo Adicional. En dicho texto se combinan - sin caer en la confusión"persona", es decir, cada individuo, y "ser humano", entendiendo este último como comprensivo de la vida humana en todas sus formas. Como ha señalado Requena Casanova, el término "persona" aparece empleado en el Convenio relativo a los Derechos Humanos y la Biomedicina en un sentido similar al utilizado en el Convenio Europeo para la Protección de los Derechos Humanos y de las Libertades Fundamentales de 11 de noviembre de $1950 .{ }^{5}$ Esto es, como sujeto de derecho y, por tanto, con derechos y obligaciones. El concepto "ser humano", por el contrario, empleado en un sentido comprensivo de la vida en todas sus formas, ofrece la posibilidad de proteger desde el mismo momento de la concepción la dignidad e identidad, y dota así de sentido práctico el artículo 13 del Convenio relativo a los Derechos Humanos y la Biomedicina que prohí-

3 Aunque finalmente no firmó este protocolo, la Santa Sede ha sostenido esta posición en su doctrina oficial. Véase: "Clonage et recherche embryonnaire", La documentation catholique, núm. $2261,2002$.

4 Véase, por ejemplo, el artículo 3 de la Carta de Derechos Fundamentales de la Unión Europea (DOCE C 364/1 y ss.), que intitulado "Derecho a la integridad de la persona" está redactado como sigue: "1. Toda persona tiene derecho a su integridad física y psíquica. 2. En el marco de la medicina y la biología se respetarán en particular: el consentimiento libre e informado de la persona de que se trate, de acuerdo con las modalidades establecidas en la ley; la prohibición de prácticas eugenésicas, y en particular las que tienen por finalidad la selección de las personas; la prohibición de que el cuerpo humano o partes del mismo en cuanto tales se conviertan en objeto de lucro; la prohibición de la clonación reproductiva de seres humanos." Adviértase que, aunque dentro del capítulo I "Dignidad", la referencia a los derechos humanos frente a la clonación humana aparece en el artículo 3 "Derecho a la integridad física" y no en el artículo 2 "Derecho a la vida", lo cual parece confirmar nuestra impresión.

5 España lo firmó el 24 de noviembre de 1977 y lo ratificó el 4 de octubre de 1979 (BOE, núm. 243, de 10 de octubre de 1979). Objeto de sucesivas modificaciones, la última de las cuales ha sido la introducida por el Protocolo Adicional núm. 11, de 11 de mayo de 1994, en vigor desde el 1o. de noviembre de 1998 — ratificado por España el 28 de noviembre de 1998 - (BOE, núm. 152, de 26 de junio de 1998; corrección de errores: BOE, núm. 223, de 17 de septiembre de 1998). 
be las manipulaciones que alteren el patrimonio genético de embriones humanos. ${ }^{6}$

En este orden de cosas, la polémica suscitada en torno a ambos términos "persona-ser humano" permitiría un acercamiento a las consideraciones éticas en conexión con la clonación humana desde una doble perspectiva complementaria y no excluyente: de una parte, tomando en consideración la dignidad del ser humano, tanto del embrión como de la persona ya nacida (2); de otra parte, considerando los derechos humanos fundamentales que son atributo inherente de la persona humana desde su nacimiento (3). ${ }^{7}$

\section{LA DIGNIDAD HUMANA COMO PUNTO \\ DE PARTIDA PARA UNA NECESARIA \\ LEGISLACIÓN INTERNACIONAL \\ EN ESTA MATERIA}

La fabricación de embriones humanos mediante el traspaso de núcleos de células somáticas, ${ }^{8}$ tanto en lo que a la clonación con fines reproductivos como terapéuticos se refiere, plantea problemas éticos con

6 Requena Casanova, M., "Nota sobre la ratificación por España del Convenio para la Protección de los Derechos Humanos y la Dignidad del Ser Humano con respecto a las aplicaciones de la Biología y la Medicina (Convenio relativo a los Derechos Humanos y a la Biomedicina)", Revista Española de Derecho Internacional, vol. LI, 1999, p. 796.

7 A la luz del artículo 1 de la Declaración Universal de los Derechos Humanos (Resolución 317 (III) de la Asamblea General de Naciones Unidas, de 10 de diciembre de 1948: "Todos los seres humanos nacen libres e iguales en dignidad y derechos y, dotados como están de razón y conciencia, deben comportarse fraternalmente los unos con los otros".

8 Como se aclara en el Informe explicativo anexo al Protocolo Adicional al Convenio relativo a los Derechos Humanos y a la Biomedicina, por el que se prohíbe la clonación humana, el precisar la clonación como la transferencia del "núcleo de una célula humana" pretende excluir a los genes mitocondríacos - que no conciernen a la identidad de una persona, de la prohibición de la clonación humana- De este modo, no se excluye a las técnicas de estimulación hormonal para tratar la infertilidad en mujeres y que pudiera dar como resultado el nacimiento de gemelos. Al haberse empleado en el párrafo segundo del artículo primero del protocolo la expresión "la misma serie de genes nucleares", los redactores del mismo han considerado que durante su desarrollo, los genes pueden sufrir una mutación somática de manera que, incluso gemelos monozigóticos, desarrollados a partir de un único huevo fertilizado, pueden no ser en un cien por ciento idénticos en cuanto a sus genes. Esta posibilidad de diferenciación, aun siendo pequeña, parece haber servido de base para una exclusión del ámbito de prohibición del protocolo a los gemelos naturales monozigótigos y su no consideración como clones humanos. Explanatory Report to the Additional Protocol to the Convention on Human Rights and Biomedicine on the Prohibition of Cloning Human Beings, Consejo de Europa, DIR/JUR (98)7, parágrafo 7. 
las células embrionarias llamadas células "madre" o pluripotentes, capaces de transformarse en cualquier célula del cuerpo humano, ${ }^{9}$ inclusive, en células reproductivas, algo que hasta fecha reciente se consideraba una frontera infranqueable. ${ }^{10}$ La obtención de las células madre y su extracción del embrión humano supone un doble dilema: de un lado está el límite de tiempo a partir del cual no debería experimentarse con esta técnica sobre el embrión humano por ser éste considerado como "persona". El desarrollo del sistema nervioso en el embrión humano a partir de los catorce días es el plazo generalmente considerado en las legislaciones que, como la del Reino Unido, Estados Unidos de América y España, ${ }^{11}$ toleran la experimentación sobre esta técnica. De otro lado, al margen de cualquier referencia temporal, está la cuestión de la inevitable muerte del embrión humano como consecuencia de la extracción de las células madre. ${ }^{12}$

$\mathrm{Ni}$ el referido artículo 13 del Convenio relativo a los Derechos $\mathrm{Hu}-$ manos y la Biomedicina, que prohíbe las manipulaciones que alteran el patrimonio genético de embriones humanos, como tampoco el artículo 2 de este mismo tratado - que no da una definición de "persona" a pesar de establecer una distinción entre ésta y "ser humano"- permiten responder a la pregunta clave relativa a si el embrión humano puede ser titular de derechos incluyendo un eventual derecho a la vida oponible a una ex-

9 Mediante un procedimiento sencillo, como explica Amy Otchet, periodista de El Correo de la Unesco: tras tomar un huevo humano cuyo núcleo (con su $\mathrm{ADN}$ o material genético) se ha extraído, se inserta en el mismo una sola célula sana obtenida de otra persona. Se hace pasar una corriente eléctrica que los fusiona y se obtiene así una bolita minúscula de células perfectas que es lisa y llanamente un embrión que podría convertirse en el clon de la persona de la que se extrajo la célula sana si se implantara en el útero de una mujer. Otchet, A., "Es ética la clonación de embriones?", El Correo de la UNESCO, abril de 2001, p. 39.

10 Como se informa en el periódico Diario de Sevilla, de 2 de mayo de 2003, acaba de aparecer publicado en la página $W e b$ de la revista estadounidense Science la noticia de que un equipo de investigadores franco-estadounidenses ha logrado producir ovocitos a partir de células madre embrionarias de ratones machos y hembras que se desarrollaron hasta los primeros estadios del embrión. Como se resalta, este experimento tiene importantes implicaciones para la investigación sobre la fertilidad y la clonación y es la primera demostración in vitro de la capacidad de las células madre de producir en laboratorio cualquier tipo de células, incluyendo las reproductivas, algo que hasta ahora no se creía posible.

11 Ley 35/1998 de Reproducción Humana Asistida, cuya reforma ha sido aprobada en el Consejo de Ministros de 25 de julio de 2003 con el fin de resolver el problema de acumulación de embriones sobrantes de los procesos de fecundación in vitro en España.

12 Otchet, A., “¿Es ética la clonación de embriones humanos?”, op. cit., nota 9, p. 40. 
perimentación sobre células madre. ${ }^{13}$ Como señalan, refiriéndose a la situación específica de Francia, Le Douarin y Puigelier, los textos legislativos en el país galo son vagos sobre la noción de persona susceptible de ejercer su derecho a la vida y a la luz de las últimas sentencias dictadas por la Corte de Casación francesa (de 13 de marzo de 1997, de 30 de junio de 1999 y de 29 de junio de 2001), el embrión humano no encuentra su sitio en una jurisprudencia que oscila entre el rechazo de su personalidad jurídica al tiempo que niega su condición de "cosa" y que deja sin resolver la cuestión de que no siendo una persona ni tampoco una cosa, ¿qué es, en consecuencia, el embrión humano? ${ }^{14}$

Sobre ésta, al igual que ocurre con otras cuestiones relacionadas con la clonación humana, el derecho debería dar una respuesta cautelar, a la espera de que la ciencia aporte datos más fehacientes que despejen la inseguridad en torno a cuándo puede hablarse de un ser humano individualizado y no de meras quimeras. Así, la aproximación seguida por el Tribunal Constitucional español con respecto al derecho a la vida, reconociendo como titular del mismo para todos los efectos únicamente al nacido (SSTC 53/1985, FJ 7; 212/1996, FJ 3), admitiendo diversas gradaciones en su protección (el llamado preembrión, embrión, feto, ser nacido) no sería válida para la salvaguardia de otros derechos como, por ejemplo, el derecho a la intimidad genética. Como ha escrito Ruiz Miguel, "si decidiéramos adoptar esa propuesta (del Tribunal Constitucional) para el derecho a la intimidad genética nos encontraríamos con la posibilidad de manipulaciones genéticas en todos los seres no nacidos. Si se dijese en favor de la propuesta de protección escalonada de la intimidad genética y de la vida que las manipulaciones o intervenciones genéticas sólo se admitirán con carácter ‘terapéutico' nos hallaríamos abocados a un inconfeso reconocimiento de la 'selección natural' pues está claro que si los diagnósticos prenatales permiten legalizar un aborto que evita a los 'peores' seres humanos por eliminación, los diagnósticos genéticos

13 Le Douarin, N. y Puigelier, C., “L'expérimentation à partir de cellules souches embryonnaires humaines", Juris Classeur Periodique. La Semaine Juridique. Édition Générale, núm. 15, 10 de abril de 2002, p. 711.

14 Ibidem, p. 715. 
preimplantatorios en el útero permiten elegir el 'mejor' de los embriones por selección". 15

Para este autor sólo cabe reconocer el derecho a la intimidad genética a todo ser humano sea cual fuere el momento de su vida puesto que "la inseguridad en este campo obliga a la prudencia. En tanto en cuanto no exista una respuesta clara, cautelarmente, debe hablarse de 'ser humano' (individualizado) desde el momento del engendramiento, pues si sólo consideramos 'ser humano' al que, por ejemplo, lleva dos meses de gestación y luego se descubriera que son también 'seres humanos' los que llevan menos tiempo de gestación, se habría causado un daño irreparable. En consecuencia, todo ser dotado de genoma humano diferenciado debe ser considerado, al menos provisionalmente, como ser humano". ${ }^{16}$

\section{LOS DERECHOS HUMANOS INALIENABLES COMO CONCRECIÓN DE LA DIGNIDAD DE TODO SER HUMANO}

A las cuestiones suscitadas en relación con el embrión humano y la dignidad intrínseca del ser humano, se suma desde un similar planteamiento ético, el temor a que la investigación y la experimentación sobre clonación humana corra el riesgo de vulnerar derechos humanos fundamentales de la persona humana. El principal de estos derechos, el derecho a la vida - al margen de cualquier consideración respecto de si su titularidad es o no predicable del ser humano no nacido, cuestión ya apuntada en el epígrafe anterior-, parece estar amenazado por la inseguridad que rodea las prácticas de experimentación genética. Es relativamente más fácil clonar una oveja que a un ser humano y, aún así, la oveja Dolly sólo fue posible tras doscientos setenta y seis intentos previos que resultaron fallidos. Todavía hoy se desconoce por qué un intento tuvo éxito frente a tan elevado número de fracasos, pero parece lógico creer que la dificultad del proceso, aunque se perfeccione en el futuro, seguirá produciendo un elevado número de intentos fallidos. Como señala May

15 Ruiz Miguel, C., "Los datos sobre características genéticas: libertad, intimidad y no discriminación", en varios autores, Genética y derecho. Estudios de derecho judicial, Consejo General del Poder Judicial, núm. 36, 2001, p. 39.

16 Ibidem, p. 40. 
Mon Post, tratándose de ovejas puede considerarse una pérdida aceptable pero parece un precio excesivamente alto tratándose de fetos humanos. ${ }^{17}$

Inseguridad respecto del periodo de gestación del feto obtenido a partir de un embrión humano clonado pero además, riesgo para la vida del ser nacido mediante tales técnicas. Como señala Susan Greenlee, aunque por el momento falta una adecuada investigación para predecir los resultados de la clonación a largo plazo, todo parece apuntar en la dirección de que un niño nacido mediante técnicas de clonación estaría expuesto a numerosos riesgos en su desarrollo y peor preparado para sobrevivir que otro niño nacido de modo "normal", ya que en los intentos pasados para clonar seres vivos han tendido a producir "seres frágiles que requerían un cuidado extremo si se quería que sobrevivieran". ${ }^{18} \mathrm{~A}$ pesar de tales cuidados, recuérdese, la célebre oveja Dolly falleció prematuramente a consecuencia de un extraño y no explicado, envejecimiento progresivo de sus células.

Además del derecho a la vida, la investigación y experimentación sobre clonación humana podría colisionar con otros derechos fundamentales. Así, por ejemplo, los riesgos antes apuntados respecto de la vida de una persona clon de otra son también extensibles al derecho de ésta al respeto de su integridad física y psíquica en la medida en que un niño clonado estaría deliberadamente privado de una "identidad social normal", ${ }^{19}$ al tiempo que puede sufrir un daño psicológico a través de una merma de su individualidad y autonomía personal. ${ }^{20}$

El derecho a la intimidad genética, entendido como el derecho de cada uno a determinar las condiciones de acceso a la información genética que le concierne, parece estar igualmente amenazado con los desarrollos en la ingeniería genética. La aproximación jurisprudencial seguida respecto del derecho a la intimidad corporal, por ejemplo, por el Tribunal Constitucional español, garantizando una inmunidad en las relaciones jurídico-públicas frente a toda indagación o pesquisa que sobre el cuerpo humano quisiera imponerse contra la voluntad de la persona, ${ }^{21}$ no sería

17 Mon Post, May, "Human Cloning: New Hope, New Implications, New Challenges", Temple International and Comparative Law Journal, vol. 15, núm. 1, 2001, p. 186.

18 Greenlee, Susan, "Dolly's Legacy to Human Cloning: International Legal Responses and Potential Human Rights Violations", Wisconsin International Law Journal, vol. 18, núm. 2, 2000, p. 552.

19 Mon Post, May, op. cit., nota 17, p. 190.

20 Greenlee, Susan, op. cit., nota 18, p. 552.

21 SSTC 37/1989, FJ 4; 120/1990, FJ 12; 137/1990, FJ 10; 207/1996, FJ 3, entre otras. 
plenamente aplicable para salvaguardar este derecho a la intimidad genética pues, como señala Ruiz Miguel, hoy día es perfectamente viable el análisis de datos genéticos a partir de células o tejidos del sujeto obtenidos sin una intervención corporal (muestras de sudor, un cabello caído, etcétera). De aquí la necesidad, en opinión de este autor que compartimos, de una noción física y no sólo cultural de la intimidad corporal y que, en consecuencia, el elemento objetivo del derecho a la intimidad genética lo constituya el genoma humano en última instancia y, por derivación, cualquier tejido o parte del cuerpo en el que se encuentre esa "información genética". ${ }^{22}$ Ante la incapacidad del derecho de los derechos humanos por dar una rápida respuesta a los desafíos de la experimentación sobre genética humana, no debe sorprender que surjan iniciativas en otras ramas del derecho, como el derecho civil o mercantil, que pretenden dar una respuesta a demandas sociales generadas en este ámbito. Así, por ejemplo, podía leerse en la prensa de finales de agosto de 2001 que una empresa estadounidense, el Instituto de Derechos de Autor de ADN en San Francisco (Estados Unidos de América) ${ }^{23}$ a cambio de mil ochocientos euros patenta el ADN humano como "derechos de autor", permitiendo con ello que cualquier persona pueda impedir su clonación al haberse asegurado que no podrá reproducirse el mapa de su código genético en ninguna parte del mundo, de conformidad con la normativa internacional en materia de derechos de autor. ${ }^{24}$

Otro derecho fundamental que parece igualmente amenazado por los avances científicos en materia de clonación humana es el derecho a no sufrir discriminación. Los defensores de la realización de modificaciones genéticas por razones preventivas o terapéuticas no creen razonable que el Estado impida que los individuos eviten tener ciertas características genéticas o transmitirlas pero, como señala Juan Rodríguez-Dincourt Álvarez, junto a la reflexión acerca de si los padres tienen derecho a tener hijos sin trastornos genéticos, ${ }^{25}$ se plantea indudablemente la cues-

22 Ruiz Miguel, C., op. cit., nota 15, p. 32.

23 Cuya dirección en Internet es www.dna-copyright.com.

24 Noticia recogida en Diario de Sevilla, edición de 28 de agosto de 2001, refiriéndose a un reportaje publicado en esta misma fecha en la revista estadounidense New Scientist.

25 Como apunta Rodríguez-Dincourt, desde el momento en que se decide seleccionar la descendencia o preferir un gen a otro se está realizando de algún modo eugenismo. Las cuestiones a dilucidar se traducen en saber si el estado puede decidir sobre el patrimonio genético de sus ciudadanos y hasta qué punto está legitimado para sostener determinadas políticas eugenésicas y 
tión de si el Estado debe o no intervenir asumiendo un papel activo de prevención y control. Si el Estado no interviene y dado el coste económico de un test genético, señala este autor, nos dirigimos hacia el modelo de desigualdad genética en el que solamente las familias con medios económicos podrán liberarse de las taras genéticas con las consiguientes discriminaciones. $^{26}$

Los más pesimistas consideran imposible embarcarse en la clonación humana sin abrir la puerta a la eugenesia en la medida en que las personas que buscaran ser clonadas podrían querer no sólo proteger a su descendencia contra determinadas enfermedades sino también "mejorarla", modificando determinados rasgos y eliminando genes no deseados. Como ha escrito Lee M. Silver, profesor de biología en la Universidad de de Princeton (Estados Unidos de América) y en la Woodrow Wilson School of Public and International Affairs, las manipulaciones genéticas se iniciarán de un modo que sea socialmente aceptable, con el tratamiento de determinadas enfermedades graves como el Alzheimer, Parkinson y otras. Posteriormente, los genetistas estudiarán el cerebro y los sentidos y al comprender mejor su funcionamiento será posible desarrollar las facultades cognitivas, reforzando, por ejemplo, el gen encargado de convertir la memoria a corto plazo en memoria a largo plazo. En una posterior etapa las manipulaciones genéticas apuntarán a introducir genes ajenos al genoma humano y así, no debe resultar descabellado pensar que, por ejemplo, gracias al traspaso de genes de murciélago, el ser humano pueda captar ondas de radio o tener visión nocturna. ${ }^{27}$ En esta dimensión de las implicaciones sociales de la clonación humana, el debate ético de sitúa en si es moralmente lícito utilizar los recursos económicos que un sector de la población posee para "mejorar" su descendencia con el consiguiente riesgo de producir una firme estamentación de la sociedad. Con respecto a la sociedad estadounidense, el debate está presente pues, como advierte el profesor Lee Silver, en un futuro próximo, con apoyo de los conocimientos actuales es posible predecir que los nacionales de ese país se hallarán divididos en dos clases: los "mejorados", cuyas familias han invertido mucho en la concepción genética de su proge-

penalizar otras por la vía administrativa o penal. Rodríguez-Dincourt Álvarez, J., Genoma humano y Constitución, Civitas, 2002, p. 58.

26 Ibidem, p. 57.

27 Silver, L. M., "Estados Unidos: bebés 'a la medida", El Correo de la UNESCO, septiembre de 1999; Bioética: ante la tentación del hijo perfecto, monográfico, p. 27. 
nie, y los "naturales", cuyas familias no han tenido los medios necesarios para hacerlo o no han querido. Los "mejorados" representarán el diez por ciento de la población y dominarán las capas superiores de la sociedad, mientras que los "naturales" se ganarán difícilmente su vida. Los padres de los "mejorados" ejercerán presión sobre sus hijos para que no dilapiden su capital genético, adquirido a precio de oro, casándose con "naturales", con lo que la división social se consolidará e incrementará progresivamente. ${ }^{28}$

En el otro extremo de las posiciones enfrentadas sobre las que se sustenta el debate ético en relación con la investigación y experimentación en materia de clonación humana, se encuentran los defensores de estas técnicas desde un punto de vista científico pero también económico. Desde la ciencia, a favor de la experimentación genética en el marco de la clonación humana se utilizan diversos argumentos de los que destacan dos: la tesis negacionista del determinismo genético y las posibilidades de tratar graves enfermedades para las que no se conoce remedio en la actualidad.

Para el determinismo genético - implícito en todos los instrumentos nacionales e internacionales que penalizan y prohíben la clonación humana- ${ }^{29}$ los genes determinan nuestra existencia jugando un papel muy limitado o ninguno en los factores ambientales en los que nos desarrollamos a lo largo de nuestra vida. El consenso entre los genetistas al respecto es que el determinismo genético es falso de manera que incluso si dos personas compartieran al cien por cien los mismos genes, cada una de ella llegaría a ser un individuo diferenciado con una personalidad propia y unas condiciones físicas en función de factores ambientales. ${ }^{30}$ En cuanto al segundo argumento a favor de los progresos en materia de clonación humana se señala que esta investigación conducirá a corto-medio plazo a la cura de enfermedades existentes como el Alzheimer, el Parkinson o la Hepatitis y se podrán obtener medicinas eficaces para el tratamiento de otras enfermedades de tipo hereditario. En consecuencia, aunque, indudablemente albergue riesgos potenciales de abuso, una prohibición sobre la investigación en este campo sería un lastre injustifi-

28 Ibidem, p. 26.

29 Bell, D., "Human Cloning and International Human Rights Law", The Sydney Law Review, vol. 21,1999 , p. 210.

30 Greenlee, S., op. cit., nota 18, p. 553. 
cable para una ciencia tan beneficiosa para la sociedad. ${ }^{31}$ En todo caso, se añade como un tercer argumento a favor de una regulación que respete la libertad de investigación en materia de clonación humana, que una prohibición podría tener como resultado la aparición de un mercado negro de la clonación en el que sería muy difícil, si no imposible, asegurar niveles de seguridad. ${ }^{32}$

Desde una perspectiva económica, los argumentos de los defensores se sustentan en el hecho de que la clonación no sólo puede ser con fines reproductivos, sino además, terapéuticos obteniendo embriones como "piezas de repuesto". De aquí el interés de algunas empresas en patentar líneas de células madre. ${ }^{33}$ Se insiste en señalar que, a este respecto, ya se toman las cautelas necesarias en la medida en que, como escribe Gómez Segade, "el derecho de patentes, como parte del ordenamiento jurídico positivo, tiene que respetar el sistema constitucional de valores en cuya cúspide se encuentran los derechos humanos. Por eso, en todas las leyes de patentes modernas se establecen limitaciones fundamentales, a través de las cuales se tienden puentes entre la ética y las innovaciones tecnológicas en el campo de la biología. Una de ella es que no sea contraria al orden público o a las buenas costumbres las invenciones cuya publicación o explotación se pretende". ${ }^{34}$

31 Mon Post, M., op. cit., nota 17, p. 193.

32 Ibidem, p. 191.

33 La fundación WARF de la Universidad de Wisconsin (Estados Unidos de América) poseía en 2001 la patente sobre cinco líneas de células y la empresa Geron Organic era propietaria de otras tantas gracias a una legislación sobre patentes que no permite patentar ni los "procedimientos de clonación de seres humanos" ni tampoco "las utilizaciones de embriones humanos con fines industriales o comerciales" pero sí "un elemento aislado del cuerpo humano u obtenido de otro modo mediante un procedimiento técnico". Apartados primero y segundo, respectivamente de la Directiva europea núm. 98-44, de 7 de julio, relativa a la protección jurídica de las invenciones biotecnológicas, Diario Oficial de las Comunidades Europeas, L 213, pp. 13-21.

34 Gómez Segade, J. A., "Patentes y bioética en la encrucijada: del onco-ratón al genoma humano", en Gómez Segade, J. A. (comp.), Tecnología y derecho. Estudios jurídicos recopilados, Madrid, Marcial Pons, 2001, p. 955. 


\section{UNA APROXIMACIÓN GLOBAL \\ E INTEGRADORA PARA UNA REGULACIÓN \\ INTERNACIONAL DE LA CLONACIÓN \\ HUMANA}

Como señalábamos al comienzo de estas páginas, causa una cierta insatisfacción en el jurista el condicionante ético en torno a la investigación y experimentación con células madre en la medida en que establece las bases de una regulación internacional de la clonación humana a partir de los postulados enfrentados - y difícilmente reconciliables - de los defensores de la dignidad humana y los derechos fundamentales del ser humano frente a los promotores del progreso en la investigación sobre el genoma humano y la flexibilidad en la aplicación del conocimiento que se deriva de dicha investigación, incluyendo su comercialización en virtud del régimen internacional de patentes. Nos parece que situar en este binomio dialéctico la clonación humana como objeto de regulación por el derecho supone una autolimitación con un coste excesivamente alto: supone renunciar a una visión integradora de todas las sensibilidades y cuestiones implicadas que interesan al derecho, frustrando así los intentos de producción normativa sobre la clonación humana que no sean meros postulados retóricos vacíos de contenido y carentes de toda eficacia en la práctica.

Indudablemente, en la clonación humana entran en juego cuestiones éticas. Las acciones que inciden sobre los seres humanos están sujetas a restricciones éticas que no dependen de un reconocimiento legal o social sino que derivan de la naturaleza misma de la humanidad. En consecuencia, en cada desarrollo científico o técnico que tenga implicaciones sociales, es importante que se respete un justo equilibrio entre lo que la sociedad puede hacer y lo que debería o no hacer. ${ }^{35}$ En la clonación humana no sólo existe un riesgo de trivialización de la vida humana, en el sentido de que los seres humanos puedan ser considerados como mercancías o artefactos (commodities and artifacts) manifestando un desinterés y una

35 Kluge, E. H., "Human Genome Research and the Law: the Ethical Basis of International Regulation”, Annual Review of Law and Ethics, 1999, núm. 7, pp. 159 y 160. 
despersonalización de la vida humana. ${ }^{36}$ Además, como se ha expuesto en las páginas precedentes, hay una amenaza real de posible violación de algunos derechos fundamentales, de modo especial, tratándose de los derechos a la vida, a la integridad física y psíquica, a no sufrir discriminación y a la intimidad genética. Estos riesgos, sin embargo, no deben impedir el reconocimiento de las posibilidades que estas técnicas genéticas ofrecen para la ciencia en orden al descubrimiento de una cura a algunas de las principales enfermedades que nos aquejan y en cuanto al desarrollo de trasplantes de órganos que no sean rechazados por el receptor de los mismos. Estos serían elementos que deben pesar también en cualquier debate ético conducente a una regulación de estas técnicas de clonación en la medida en que, como se reconoce en diversos instrumentos internacionales de protección de derechos humanos, ${ }^{37}$ el derecho al disfrute del más alto nivel posible de salud física y mental es, igualmente, un derecho fundamental del ser humano.

La experiencia del pasado muestra que frente a los nuevos descubrimientos científicos son posibles cuatros respuestas legales, como señala Susan Martyn: el incentivo de la actividad mediante la financiación gubernamental y la protección de patentes; la abstención reguladora, consecuente con el laissez faire de la revolución industrial del siglo XIX; la opción de la regulación legal, controlando y desincentivando una actividad o parte de la misma, como sucedió a raíz de la Gran Depresión de 1929 que siguió a la expansión económica sin precedentes del siglo XIX; finalmente, la cuarta opción posible sería la que más frecuentemente se habría repetido en el pasado: la prohibición de la idea o descubrimiento en cuestión. ${ }^{38}$ De las cuatro, la prohibición y la abstención reguladora no

36 Mon Post, M., op. cit., nota 17, p. 191.

37 Párrafo 1 del artículo 25 de la Declaración Universal de los Derechos Humanos; artículo 12 del Pacto Internacional de Derechos Económicos Sociales y Culturales; artículo 24 de la Convención sobre los Derechos del Niño y artículo 12 de la Convención sobre la Eliminación de todas las Formas de Discriminación contra la Mujer. En este sentido, debe mencionarse que en su Resolución 2002/31, la Comisión de Derechos Humanos de Naciones Unidas decidió nombrar, por un periodo de tres años, al señor Paul Hunt como relator especial, centrándose su mandato en el derecho de toda persona al disfrute del más alto nivel posible de salud física y mental. Su primer informe es de 13 de febrero de 2003 (E/CN.4/2003/58).

38 Martyn, S. R., "Human Cloning: the Role of Law", University of Toledo Law Review, vol. 32,2001, p. 375. 
parecen ser opciones particularmente aconsejables por los riesgos de la aparición de un mercado negro de la clonación humana o de creación de santuarios de experimentación genética, verdaderas versiones modernas de islas del "Doctor Moreau", en las que, ajenas a control alguno, puedan practicarse aberrantes actos con seres humanos. La respuesta legal de incentivos mediante apoyo gubernamental y la protección de patentes no es descartable a priori pero parece claramente insuficiente si no va acompañada de la que nos parece la aproximación legal más conveniente para la clonación humana: su regulación normativa.

La regulación normativa de la clonación humana, por la propia naturaleza de su objeto material, ha de reunir una doble característica: de una parte ha de tener un planteamiento ético en la base de su formulación. ${ }^{39}$ Esto es, reconoce que la clonación puede ser beneficiosa para la sociedad si se traza una estricta línea que asegure que la tecnología no conduzca a lo que es moralmente inaceptable, al mismo tiempo que se preserva el avance de la ciencia. ${ }^{40}$

De otra parte, la regulación propuesta debe, a su vez, cumplir el requisito de ser establecida a escala universal, a partir de principios y valores que pueden ser compartidos por todos los Estados de la comunidad internacional en su conjunto. Esto sería aconsejable por dos razones: la primera es obvia, un examen comparativo de la diversidad de prácticas nacionales en materia de investigación y experimentación sobre la clonación humana permite concluir que sin cooperación internacional cualquier esfuerzo a nivel de regulación nacional no tendrá éxito porque siempre habrá un lugar donde la clonación humana esté permitida. ${ }^{41} \mathrm{La}$ segunda razón es que, como señala Noëlle Lenoir, tras la Declaración Universal sobre el Genoma Humano y los Derechos Humanos, elaborada en la UNESCO entre 1993 y 1997, a la que se adhirió la Asamblea General

39 Kluge, E. H., op. cit., nota 35, pp. 159 y 160.

40 Mon Post, M., op. cit., nota 17, p. 193.

41 Hawkins, A., "Protecting Human Dignity and Individuality: the Need for Uniformity in International Cloning Legislation", The Transnational Lawyer, vol. 14, 2001, p. 293. 
de Naciones Unidas el 9 de diciembre de 1998, ha puesto de manifiesto que la bioética ha dejado de ser un asunto de interés puramente interno de los Estados. ${ }^{42}$

Una regulación a nivel internacional de la clonación humana, que esté sustentada sobre la base de principios y valores susceptibles de ser compartidos por un elevado número de Estados, se encuentra con varios obstáculos, de modo particular dos: el primero sería la presencia de múltiples actores interesados en esta cuestión; junto a los Estados y las organizaciones internacionales cobran un relevante papel personas individuales (por ejemplo, el doctor Antinori, quien defiende públicamente sus intentos de obtener un clon humano vivo); grupos de particulares (como la secta de los raelianos que oferta la clonación a sus adeptos), así como empresas trasnacionales (poseedoras de laboratorios o de centros privados de investigación, como Geron Dynamics). El segundo obstáculo es, en parte, consecuencia del anterior: la falta de consenso sobre los contenidos esenciales de la eventual regulación internacional de la clonación humana.

La presencia distorsionadora de una pluralidad de actores que participan a nivel internacional en la investigación en materia de clonación humana y en la aplicación del conocimiento que se deriva de dicha investigación, así como la ausencia de un consenso entre los principales de estos actores, los Estados, puede servir para explicar las características peculiares de la respuesta que desde el derecho internacional se ha dado a la clonación humana. Así, por ejemplo, en los pocos casos en los que se ha materializado esa respuesta en una norma convencional, ha prevalecido el tratado marco a desarrollar a nivel interno por los Estados parte, con el consiguiente riesgo, apuntado por el profesor Fernández De Casadevante Romaní, de que en el resultado de dicho desarrollo se llegue a diferentes niveles de protección entre los Estados. ${ }^{43}$ En la mayoría de las

42 Lenoir, Noëlle, "Universal Declaration on the Human Genome and Human Rights: the First Legal and Ethical Framework at the Global Level”, Columbia Human Rights Law Review, vol. 30, 1999 , p. 577.

43 Fernández De Casadevante Romaní, C., "The Convention on the Protection of Human Rights and the Dignity of the Human Being in regard to Applications of Biology and Medicine: Convention on Human Rights and Biomedicine", Law and Human Genome Review, 1997, núm. 7, p. 112. 
veces, por el contrario, se ha preferido la vía de resoluciones elaboradas en el seno de organizaciones internacionales, tanto de carácter universal como regional. La mayoría de estas resoluciones no tiene fuerza jurídica vinculante pero se aspira a que sirvan de estímulo para que los Estados asuman los principios en ellas enunciados - incorporándolos en su legislación interna- Permiten, además, superar la negativa de los Estados a quedar vinculados por obligaciones internacionales en áreas sensibles o nuevas, facilitando el acuerdo entre los Estados para alcanzar un consenso internacional en materia de clonación humana.

\section{CONCLUSIONES}

Al finalizar estas páginas varias, son las conclusiones alcanzadas con el presente estudio:

Primera. La regulación que se ha dado a la clonación humana tanto a nivel interno como internacional, se encontraría en gran medida influenciada por el debate dialéctico de dos postulados enfrentados: de un lado, el que propugna la libertad absoluta de la ciencia, auspiciada en gran medida ante las expectativas de la rentabilidad económica derivada de la libre comercialización de los descubrimientos que puedan realizarse. De otro lado, el que representan los defensores de los derechos humanos inalienables, que se piensan están expuestos a un grave riesgo de vulneración si se permite dicha experimentación e investigación genética.

Segunda. El aceptar reducir el debate acerca de la clonación humana a una dialéctica entre los defensores de la dignidad humana y los derechos inalienables del ser humano frente a los que promueven los avances de la ciencia y la comercialización en virtud del régimen internacional de patentes de los posibles descubrimientos que puedan obtenerse, supone empobrecerlo y arriesgarse a que los eventuales intentos de materializarlo en resultados concretos sólo sean mera retórica vacía de contenido y carente de toda eficacia en la práctica.

Tercera. Como se ha intentado mostrar en el presente estudio resulta erróneo plantear un discurso sobre la clonación humana sustentado en el binomio que contrapone ciencia-mercado a ética-moral. Por el contrario, se ha apuntado la necesidad de optar por una aproximación global, integradora y más coherente con la multiplicidad de la pluralidad de cuestio- 
nes - incluso de aquellas que molesten, choquen o resulten indiferentes - en la investigación y experimentación en materia de clonación humana. Dicha regulación sólo puede venir, por las razones analizadas en las páginas precedentes, por el derecho internacional. 